\title{
Exclusión social entre las personas con discapacidad física de Gipuzkoa: datos y conclusiones para el diseño de políticas sociales
}

\author{
elkartu-Federación Coordinadora de Personas con Discapacidad Física \\ de Gipuzkoa / Gipuzkoako Gutxitasun Fisikoa duten Pertsonen Federazio \\ Koordinatzailea \\ <elkartu@elkartu.org>
}

Gipuzkoan ezgaitasun fisikoa duten pertsonen kolektiboa aztertu eta karakterizatzeko, modu independentean eta aukera berdintasunean bizitzeko beharrak eta eskaerak ezagutzeko, eta erabateko inklusioa lortzeko ezgaitasun arloko politika publikoen eraginkortasuna aztertzeko elkartuk egindako ikerketa laburtzen du artikulu honek. Emaitzek kolektibo honetan bazterketa soziala, biztanleria guztiaren aldean, neurri handiagoan ematen dela azaltzen dute, baita ere egoera horiek faktore sozialek eragiten dituztela, elkarbizitza edota pertsonalei lotutakoek baino. Bazterketa egoera edo arriskuan dauden pertsonentzako diseinatu eta ezartzen diren politika publikoak giza eskubideen ikuspegian oinarritzeko beharra ondorioztatzen du ikerketak.

\section{GAKO-HITZAK:}

Ezgaitasuna, inklusioa, bazterkeria, berdintasuna, eskubideak.
Este artículo resume una investigación realizada por elkartu con el objetivo de, por una parte, estudiar y caracterizar el colectivo de personas con discapacidad física de Gipuzkoa, y por otra, identificar y abordar sus necesidades y demandas para llevar a cabo una vida independiente y en igualdad de oportunidades, así como determinar la eficacia de las políticas públicas en materia de discapacidad, con el objetivo de alcanzar la plena inclusión social. Los resultados muestran una incidencia notablemente superior de las situaciones de exclusión social en el citado colectivo cuando se compara con la población general, y ponen de relieve que tales situaciones obedecen principalmente a factores sociales más que a factores convivenciales y personales. La investigación concluye reclamando la imperiosa necesidad de que las políticas públicas orientadas a las personas en situación o riesgo de exclusión social se diseñen e implementen desde un enfoque basado en los derechos humanos.

\section{Palabras ClaVe:}

Discapacidad, inclusión, exclusión, igualdad, derechos. 


\section{Introducción}

Este artículo resume el Estudio-diagnóstico de situación y necesidades de las personas con discapacidad física de Gipuzkoa, realizado por elkartu (Federación Coordinadora de Personas con Discapacidad Física de Gipuzkoa) y publicado en 2015. La investigación perseguía, por una parte, estudiar y caracterizar el colectivo de personas con discapacidad física de Gipuzkoa, y por otra, identificar y abordar sus necesidades y demandas para llevar a cabo una vida independiente y en igualdad de oportunidades, así como determinar la eficacia de las políticas públicas en materia de discapacidad, con el objetivo de alcanzar la plena inclusión social. Los resultados del estudio debían servir de fundamento a la Federación para reclamar, ante las instituciones públicas, los agentes privados y la sociedad en su conjunto, la adopción de políticas, medidas y actitudes que favorecieran la plena inclusión y participación social de las personas con discapacidad física.

Los ámbitos objeto de análisis y valoración fueron los siguientes:

- Perfil sociodemográfico.

- Discapacidad y dependencia.

- Residencia habitual y asistencia en las actividades básicas de la vida diaria.

- Educación/formación.

- Situación laboral.

- Situación económica.

- Productos de apoyo y ayudas a la movilidad.

- Ocio y participación comunitaria.

- Transporte

- Protección de la salud.

- Diagnóstico de exclusión social.

- Percepción del género y la discapacidad física.

El estudio respondía a la necesidad, insuficientemente abordada, de impulsar la investigación en torno a las políticas de discapacidad. Así, la Convención sobre los Derechos de las Personas con Discapacidad, aprobada en Nueva York el 13 de diciembre de 2006, establece que "los Estados Partes recopilarán información adecuada, incluidos datos estadísticos y de investigación, que les permita formular y aplicar políticas, a fin de dar efecto a la presente Convención" (art. 31.1), mientras que la Estrategia Europea sobre Discapacidad (2010-2020) prescribe una serie de medidas en los ámbitos primordiales de actuación identificados (accesibilidad, participación, igualdad, empleo, educación y formación, protección social, sanidad y acción exterior). Dichas medidas se sustentan en determinados instrumentos generales, entre los que se incluyen las estadísticas y la recopilación y seguimiento de datos, estableciéndose que "la actuación de la UE apoyará y complementará los esfuerzos de los Estados miembros por recoger datos y elaborar estadísticas que pongan de relieve las barreras que impiden a las personas con discapacidad ejercer sus derechos".

En el ámbito del País Vasco, el art. 6 de la Ley $12 / 2008$, de 5 de diciembre, de Servicios Sociales, establece que se articularán mecanismos orientados a "detectar las necesidades sociales susceptibles de ser atendidas en el ámbito de los servicios sociales y planificar los servicios y prestaciones más idóneas para responder a dichas necesidades". Asimismo, se recoge el apoyo público a la iniciativa social sin ánimo de lucro para el desarrollo de prestaciones y servicios no incluidos en el Catálogo de Prestaciones y Servicios del Sistema Vasco de Servicios Sociales, y la realización de otras actividades en el ámbito de los servicios sociales, siendo objeto de especial consideración "las actividades de investigación, desarrollo e innovación orientadas a la mejora de la planificación, a la garantía y mejora de la calidad en la organización de servicios y en la prestación de la atención, y a la mejora de las prácticas profesionales" (art. 73.2).

\section{Metodología}

El estudio se llevó a cabo con una muestra de 102 personas con discapacidad física, siguiendo para ello una técnica de muestreo no probabilístico, dada la inexistencia de un censo o registro administrativo con información sobre el conjunto de personas con discapacidad física en Gipuzkoa. La investigación combinó la metodología cuantitativa y la cualitativa. Así, la metodología cuantitativa, a través de cuestionarios cumplimentados por el personal técnico, permitió recoger datos cuantificables de las diferentes áreas analizadas. Por su parte, la metodología cualitativa, mediante entrevistas individuales y grupos de discusión, permitió recoger los aspectos subjetivos y la forma en que las personas con discapacidad física experimentaban los aspectos relativos a cada área objeto de estudio.

\section{Aplicación de herramientas de diagnóstico de exclusión social: datos y conclusiones para el diseño de políticas sociales en materia de discapacidad}

Profundizar en el conocimiento de la relación existente entre discapacidad física y exclusión social, conceptuada ésta desde un punto de vista multidimensional y procesual, constituye un reto fundamental para avanzar en las políticas dirigidas a conseguir la plena incorporación y participación social del colectivo de personas con discapacidad. Así, la medición cuantitativa de la exclusión social, es decir, del grado de exclusión que una persona padece, se presenta como un reto decisivo para analizar la situación de partida de la sociedad en su 
conjunto y de aquellos colectivos, entre los que se encuentran las personas con discapacidad física, que reúnen mayores factores que pueden dar lugar a procesos de exclusión social.

Para ello, el Decreto 385/2013, de 16 de julio, aprobó el Instrumento de Valoración de la Exclusión Social que, basado en un sistema de indicadores, sirve para valorar con criterios comunes la existencia de situaciones de exclusión social o de riesgo de exclusión social. Valiéndose de esta herramienta, el Estudio-diagnóstico de situación y necesidades de las personas con discapacidad física de Gipuzkoa afrontó el reto de determinar objetivamente la situación en la que se encontraban las personas con discapacidad física desde la perspectiva de la exclusión social, determinando desde el punto de vista cuantitativo y cualitativo las situaciones de inclusión social, de riesgo de exclusión y de exclusión social.

El Instrumento de Valoración de la Exclusión Social toma en consideración cinco ámbitos vitales (económico, convivencial, personal, salud y social), y de su aplicación se derivan las siguientes categorías diagnósticas:

- Situación de inclusión social: tiene que ver con el acceso adecuado a los sistemas de protección social existentes, con la facilidad que tienen las personas para utilizar la información precisa para acceder a los derechos y deberes ciudadanos que le corresponden, con las capacidades personales y sociales para relacionarse, y con la participación social. Además de implicar la activación de las personas en la producción y consumo de bienes sociales, lleva consigo la participación activa en la sociedad, su toma de conciencia ciudadana, su capacidad de elegir y tomar decisiones, o su implicación como miembros de la comunidad.

- Situación de riesgo de exclusión social: se entiende que tiene que ver con la presencia o ausencia de una serie de características o factores personales o sociales que hacen que aumenten las probabilidades de aparición de consecuencias adversas que deriven en situaciones o procesos de exclusión social.
- Situación de exclusión social: las personas se encuentran en situación de exclusión social cuando sus condiciones de vida y convivencia se están viendo afectadas por múltiples déficits y carencias que persisten en el tiempo y que, al acumularse, provocan una situación de exclusión social que está relacionada directamente con los recursos personales, relacionales y materiales. Según su intensidad, la exclusión puede ser leve, moderada o grave.

Tras aplicar el Instrumento de Valoración a las 102 personas con discapacidad física entrevistadas, cabe destacar que el $69,6 \%$ se encontraba en situación o riesgo de exclusión social (Tabla 1).

En lo que se refiere a la intensidad de la exclusión, la proporción de los tres grados era similar desde el punto de vista cuantitativo, aunque cabe subrayar que un $10,8 \%$ de las personas con discapacidad física entrevistadas se encontraban en situación de exclusión social grave (Gráfico 1).

Gráfico 1. Intensidad de las situaciones de exclusión

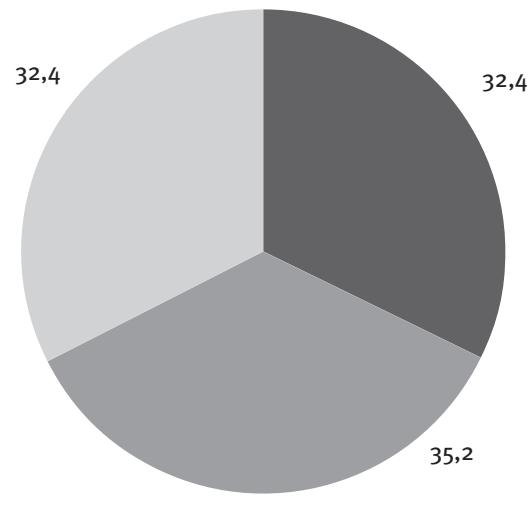

Exclusión leve Exclusión moderada Exclusión grave

Fuente: Elaboración propia.

Tabla 1. Valoración de la situación de inclusión/exclusión social, según sexo y origen de la discapacidad

\begin{tabular}{|c|c|c|c|c|c|c|c|c|c|c|c|c|}
\hline & \multicolumn{6}{|c|}{ Sexo } & \multicolumn{6}{|c|}{ Origen de la discapacidad } \\
\hline & \multicolumn{2}{|c|}{ M } & \multicolumn{2}{|c|}{$\mathbf{v}$} & \multicolumn{2}{|c|}{ Total } & \multicolumn{2}{|c|}{ Congénita } & \multicolumn{2}{|c|}{ Sobrevenida } & \multicolumn{2}{|c|}{ Total } \\
\hline & $\mathbf{N}$ & $\%$ & $\mathbf{N}$ & $\%$ & N & $\%$ & $\mathbf{N}$ & $\%$ & $\mathbf{N}$ & $\%$ & $\mathbf{N}$ & $\%$ \\
\hline Inclusión social & 20 & 39,2 & 11 & 21,6 & 31 & 30,4 & 11 & 21,6 & 20 & 39,2 & 31 & 30,4 \\
\hline $\begin{array}{l}\text { Riesgo de exclusión } \\
\text { social }\end{array}$ & 17 & 33,3 & 20 & 39,2 & 37 & 36,3 & 19 & 37,3 & 18 & 35,3 & 37 & 36,3 \\
\hline Exclusión social & 14 & 27,5 & 20 & 39,2 & 34 & 33,3 & 21 & 41,2 & 13 & 25,5 & 34 & 33,3 \\
\hline $\mathrm{NS} / \mathrm{NC}$ & 0 & 0,0 & 0 & 0,0 & 0 & 0,0 & 0 & 0,0 & 0 & 0,0 & o & 0,0 \\
\hline Total & 51 & 50,0 & 51 & 50,0 & 102 & 100,0 & 51 & 50,0 & 51 & 50,0 & 102 & 100,0 \\
\hline
\end{tabular}

Fuente: Elaboración propia. 
En este punto, resulta importante señalar que la intensidad de la situación de exclusión social determina la distancia social que existe entre la posición social en zona de exclusión y la que se considera posición de inclusión social, recogiéndose tres posiciones, que oscilan desde la precariedad o vulnerabilidad más leve hasta las situaciones de exclusión más graves:

- Exclusión social leve: desarraigo inicial o leve. Personas que disponen de contactos muy frágiles con sus familiares o con la red social de apoyo.

- Exclusión social moderada: fase avanzada de desarraigo. Personas que han roto sus lazos sociales básicos.

- Exclusión social grave: forma de vivir en sociedad sin participar en ella, por la precariedad o ausencia de las relaciones sociales y afectivas. Significa sentirse o no contar para nada, sentirse o no ser considerado útil a la sociedad, sentirse o ser descartado de la participación y, sobre todo, sentirse insignificante.

Por lo que se refiere a la variable del grado de discapacidad (Tabla 2), los grados más elevados acumulaban las mayores situaciones de exclusión social, aunque no puede obviarse el importante porcentaje de personas (42,9\%) que tenían valorada su discapacidad con un grado inferior al $65 \%$ y que se encuentran en riesgo de exclusión.

También al abordar la situación de exclusión social, se observa que las personas con discapacidad física que hacían uso de un recurso residencial de carácter permanente se encontraban en un estado de mayor precariedad que quienes residían en su propia vivienda (Tabla 3). Así, ninguna de las personas entrevistadas usuarias de un alojamiento residencial se encontraba en situación de inclusión social, resultando asimismo revelador que un $75 \%$ estaba en situación de exclusión.

Respecto a la intensidad de la exclusión de quienes hacían uso de los recursos residenciales, cabe señalar que el 33,3\% se encontraba en situación de exclusión leve; el $46,7 \%$, en exclusión moderada; y el $20 \%$, en exclusión grave.

En contraposición con estos datos, cabe indicar que quienes participaban en el Programa de Vida Independiente, cuyo objeto es optar por un modelo de vida que promueva la autonomía personal en el entorno natural evitando la institucionalización se encontraban en una situación notablemente más favorable en lo que a niveles de inclusión social se refiere (Gráfico 2).

El estudio permitió acreditar también el carácter decisivo de la formación para determinar las situaciones de inclusión o exclusión social entre las personas con discapacidad física (Tabla 4). Así, conforme aumentaba el nivel de estudios de las personas entrevistadas, disminuían las posibilidades de encontrarse en situaciones de riesgo o exclusión social, resultando significativo que un $72,7 \%$ de personas que no tenían estudios se encontraran en situación de exclusión social. Dentro de este grupo, el $12,5 \%$ se hallaba en situación de exclusión leve; el $25 \%$, en exclusión moderada; y el $62,5 \%$, en exclusión grave.

Tabla 2. Valoración de la situación de inclusión/exclusión social, según grado discapacidad

\begin{tabular}{|l|c|c|c|c|c|c|c|c|}
\multicolumn{1}{c|}{} & \multicolumn{2}{c}{$33 \%-64 \%$} & \multicolumn{2}{c|}{$65 \%-74 \%$} & \multicolumn{2}{c|}{$>$ 74\% } & \multicolumn{2}{c|}{ Total } \\
\cline { 2 - 10 } \multicolumn{1}{c|}{} & $\mathbf{N}$ & $\%$ & $\mathbf{N}$ & $\%$ & $\mathbf{N}$ & $\%$ & $\mathbf{N}$ & $\%$ \\
\hline Inclusión social & 13 & 46,4 & 4 & 40,0 & 14 & 21,9 & 31 & 30,4 \\
\hline Riesgo de exclusión social & 12 & 42,9 & 2 & 20,0 & 23 & 35,9 & 37 & 36,3 \\
\hline Exclusión social & 3 & 10,7 & 4 & 40,0 & 27 & 42,2 & 34 & 33,3 \\
\hline NS/NC & 0 & 0,0 & 0 & 0,0 & 0 & 0,0 & 0 & 0,0 \\
\hline Total & 28 & 27,5 & 10 & 9,8 & 64 & 62,7 & 102 & 100,0 \\
\hline
\end{tabular}

Fuente: Elaboración propia.

Tabla 3. Valoración de la situación de inclusión/exclusión social según lugar de residencia

\begin{tabular}{|c|c|c|c|c|c|c|}
\hline & \multicolumn{2}{|c|}{$\begin{array}{l}\text { Vivienda } \\
\text { particular }\end{array}$} & \multicolumn{2}{|c|}{ Centro residencial } & \multicolumn{2}{|c|}{ Total } \\
\hline & $\mathbf{N}$ & $\%$ & $\mathbf{N}$ & $\%$ & $\mathbf{N}$ & $\%$ \\
\hline Inclusión social & 31 & 37,8 & 0 & 0,0 & 31 & 30,4 \\
\hline Riesgo de exclusión social & 32 & 39,0 & 5 & 25,0 & 37 & 36,3 \\
\hline Exclusión social & 19 & 23,2 & 15 & 75,0 & 34 & 33,3 \\
\hline $\mathrm{NS} / \mathrm{NC}$ & 0 & 0,0 & 0 & 0,0 & 0 & 0,0 \\
\hline Total & 82 & 80,4 & 20 & 19,6 & 102 & 100,0 \\
\hline
\end{tabular}

Fuente: Elaboración propia. 
Gráfico 2. Valoración de la situación de inclusión/

exclusión social entre las personas beneficiarias del

Programa de Vida Independiente (\%)

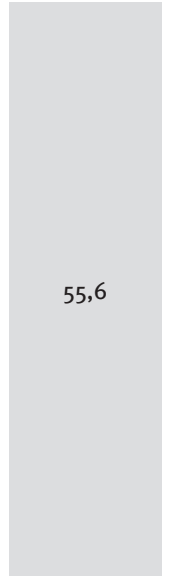

Inclusión social

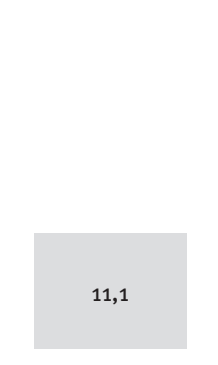

Riesgo de exclusión social

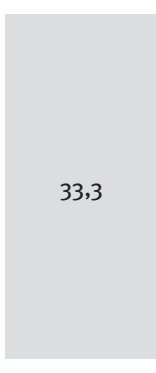

Exclusión social
Fuente: Elaboración propia.
Por lo que se refiere a la variable de la ocupación (Tabla 5), se observa que quienes trabajaban tenían un índice de inclusión social notablemente superior a quienes estaban en desempleo y a quienes tenían la condición de pensionistas, siendo éstos últimos los que presentaban mayores niveles de exclusión, dado que el $72,2 \%$ se encontraba en situación o riesgo de exclusión social.

En lo referido a la situación económica (Tabla 6), de los datos relativos a los niveles de pobreza a continuación expuestos se concluye que, aun existiendo un estrecho vínculo entre la situación económica o de pobreza y la situación de exclusión social (por ejemplo, ninguna de las personas que, se encontraban en pobreza grave estaba en situación de inclusión social), el factor económico no conlleva per se una situación de exclusión social, dado que, por ejemplo, el 31,1\% de las personas en ausencia de pobreza se encontraban, a su vez, en situación de exclusión social. Ello no hace sino confirmar la multidimensionalidad de las situaciones de exclusión/inclusión social, en cuya concurrencia intervienen factores diversos e íntimamente relacionados entre sí, y que determinan el grado de inclusión y participación social.

Tabla 4. Valoración de la situación de inclusión/exclusión social, según nivel de formación

\begin{tabular}{|c|c|c|c|c|c|c|c|c|c|c|c|c|c|c|}
\hline & \multicolumn{2}{|c|}{ Sin estudios } & \multicolumn{2}{|c|}{$\begin{array}{c}\text { Educación } \\
\text { primaria }\end{array}$} & \multicolumn{2}{|c|}{$\begin{array}{l}\text { Educación } \\
\text { secundaria }\end{array}$} & \multicolumn{2}{|c|}{$\begin{array}{l}\text { Formación } \\
\text { profesional }\end{array}$} & \multicolumn{2}{|c|}{$\begin{array}{c}\text { Estudios } \\
\text { universitarios }\end{array}$} & \multicolumn{2}{|c|}{ Otros } & \multicolumn{2}{|c|}{ Total } \\
\hline & $\mathbf{N}$ & $\%$ & $\mathbf{N}$ & $\%$ & $\mathbf{N}$ & $\%$ & $\mathbf{N}$ & $\%$ & $\mathbf{N}$ & $\%$ & $\mathbf{N}$ & $\%$ & $\mathbf{N}$ & $\%$ \\
\hline Inclusión social & 2 & 18,2 & 12 & 32,4 & 2 & 22,2 & 7 & 25,9 & 8 & 47,1 & 0 & 0,0 & 31 & 30,4 \\
\hline $\begin{array}{l}\text { Riesgo de exclusión } \\
\text { social }\end{array}$ & 1 & 9,1 & 12 & 32,4 & 4 & 44,4 & 14 & 51,9 & 5 & 29,4 & 1 & 100,0 & 37 & 36,3 \\
\hline Exclusión social & 8 & 72,7 & 13 & 35,1 & 3 & 33,3 & 6 & 22,2 & 4 & 23,5 & 0 & 0,0 & 34 & 33,3 \\
\hline $\mathrm{NS} / \mathrm{NC}$ & 0 & 0,0 & 0 & 0,0 & 0 & 0,0 & 0 & 0,0 & 0 & 0,0 & 0 & 0,0 & 0 & 0,0 \\
\hline Total & 11 & 10,8 & 37 & 36,3 & 9 & 8,8 & 27 & 26,5 & 17 & 16,7 & 1 & 1,0 & 102 & 100,0 \\
\hline
\end{tabular}

Fuente: Elaboración propia.

Tabla 5. Valoración de la situación de inclusión/exclusión social, según situación laboral

\begin{tabular}{|c|c|c|c|c|c|c|c|c|c|c|c|c|}
\hline & \multicolumn{2}{|c|}{ Trabajando } & \multicolumn{2}{|c|}{$\begin{array}{l}\text { Desempleo, } \\
\text { búsqueda activa } \\
\text { de empleo }\end{array}$} & \multicolumn{2}{|c|}{ Pensionista } & \multicolumn{2}{|c|}{$\begin{array}{l}\text { Compatibiliza } \\
\text { pensión y } \\
\text { trabajo }\end{array}$} & \multicolumn{2}{|c|}{ Otros } & \multicolumn{2}{|c|}{ Total } \\
\hline & $\mathbf{N}$ & $\%$ & $\mathbf{N}$ & $\%$ & $\mathbf{N}$ & $\%$ & $\mathbf{N}$ & $\%$ & N & $\%$ & $\mathbf{N}$ & $\%$ \\
\hline Inclusión social & 4 & 66,7 & 5 & 33,3 & 22 & 27,8 & 0 & 0,0 & 0 & 0,0 & 31 & 30,4 \\
\hline $\begin{array}{l}\text { Riesgo de exclusión } \\
\text { social }\end{array}$ & 1 & 16,7 & 8 & 53,3 & 27 & 34,2 & 0 & 0,0 & 1 & 50,0 & 37 & 36,3 \\
\hline Exclusión social & 1 & 16,7 & 2 & 13,3 & 30 & 38,0 & 0 & 0,0 & 1 & 50,0 & 34 & 33,3 \\
\hline $\mathrm{NS} / \mathrm{NC}$ & 0 & 0,0 & 0 & 0,0 & 0 & 0,0 & 0 & 0,0 & 0 & 0,0 & 0 & 0,0 \\
\hline Total & 6 & 5,9 & 15 & 14,7 & 79 & 77,5 & 0 & 0,0 & 2 & 2,0 & 102 & 100,0 \\
\hline
\end{tabular}

Fuente: Elaboración propia. 
Al igual que otros ámbitos abordados en el estudio, la situación de inclusión/exclusión social también fue objeto de comparación con los datos de la población de Gipuzkoa (Tabla 7). Para ello, y a pesar de las diferencias metodológicas utilizadas, se confrontaron los resultados obtenidos, basados en el Instrumento de Valoración de la Exclusión Social aprobado por el Gobierno Vasco (Decreto 385/2013), con los reflejados en la Encuesta de Pobreza y Exclusión Social de Gipuzkoa 2012, que hace uso del sistema de indicadores de exclusión de la Fundación Foessa (Lorenzo Gilsanz, 2014).

Los datos ponen de manifiesto una incidencia notablemente superior de las situaciones de exclusión social entre las personas con discapacidad física, en comparación con el conjunto de la población, por lo que la discapacidad se constata como un componente determinante para que las distintas dimensiones que inciden en las situaciones de inclusión o exclusión social inclinen la balanza hacia procesos de exclusión o alejamiento de los ámbitos de participación social y pleno ejercicio de los derechos de ciudadanía.

Por otra parte, resulta trascendental no caracterizar únicamente la situación del colectivo de personas con discapacidad física desde el punto de vista de la inclusión/exclusión social, sino abordar también las razones que desencadenan una situación u otra (Gráfico 3). El Instrumento de Valoración de la Exclusión Social establece tres indicadores para

Tabla 6. Valoración de la situación de inclusión/exclusión social, según situación de pobreza

\begin{tabular}{|l|c|c|c|c|c|c|c|c|c|c|}
\cline { 2 - 12 } \multicolumn{1}{c|}{} & \multicolumn{2}{c|}{ Ausencia pobreza } & \multicolumn{2}{c|}{ Pobreza relativa } & \multicolumn{2}{c|}{ Pobreza grave } & \multicolumn{2}{c|}{ NS/NC } & \multicolumn{2}{c|}{ Total } \\
\cline { 2 - 12 } \multicolumn{1}{c|}{} & $\mathbf{N}$ & $\%$ & $\mathbf{N}$ & $\%$ & $\mathbf{N}$ & $\%$ & $\mathbf{N}$ & $\%$ & $\mathbf{N}$ & $\%$ \\
\hline Inclusión social & 26 & 35,1 & 4 & 30,8 & 0 & 0,0 & 1 & 100,0 & 31 & 30,4 \\
\hline $\begin{array}{l}\text { Riesgo de exclusión } \\
\text { social }\end{array}$ & 25 & 33,8 & 7 & 53,8 & 5 & 35,7 & 0 & 0,0 & 37 & 36,3 \\
\hline Exclusión social & 23 & 31,1 & 2 & 15,4 & 9 & 64,3 & 0 & 0,0 & 34 & 33,3 \\
\hline NS/NC & 0 & 0,0 & 0 & 0,0 & 0 & 0,0 & 0 & 0,0 & 0 & 0,0 \\
\hline Total & 74 & 72,5 & 13 & 12,7 & 14 & 13,7 & 1 & 1,0 & 102 & 100,0 \\
\hline
\end{tabular}

Fuente: Elaboración propia.

Tabla 7. Tasas de inclusión/exclusión de la población de Gipuzkoa (\%)

\begin{tabular}{|c|c|c|}
\hline & Población total & $\begin{array}{c}\text { Población con } \\
\text { discapacidad física }\end{array}$ \\
\hline Integración/Inclusión & 55,8 & 30,4 \\
\hline Integración precaria/riesgo de exclusión & 31,8 & 36,3 \\
\hline Exclusión & 12,4 & 33,3 \\
\hline Total & 100,0 & 100,0 \\
\hline
\end{tabular}

Fuentes: Elaboración propia a partir de los datos recogidos y de SIIS Centro de Documentación y Estudios (2013).

Gráfico 3. Factores determinantes en la inclusión/exclusión social (\%)

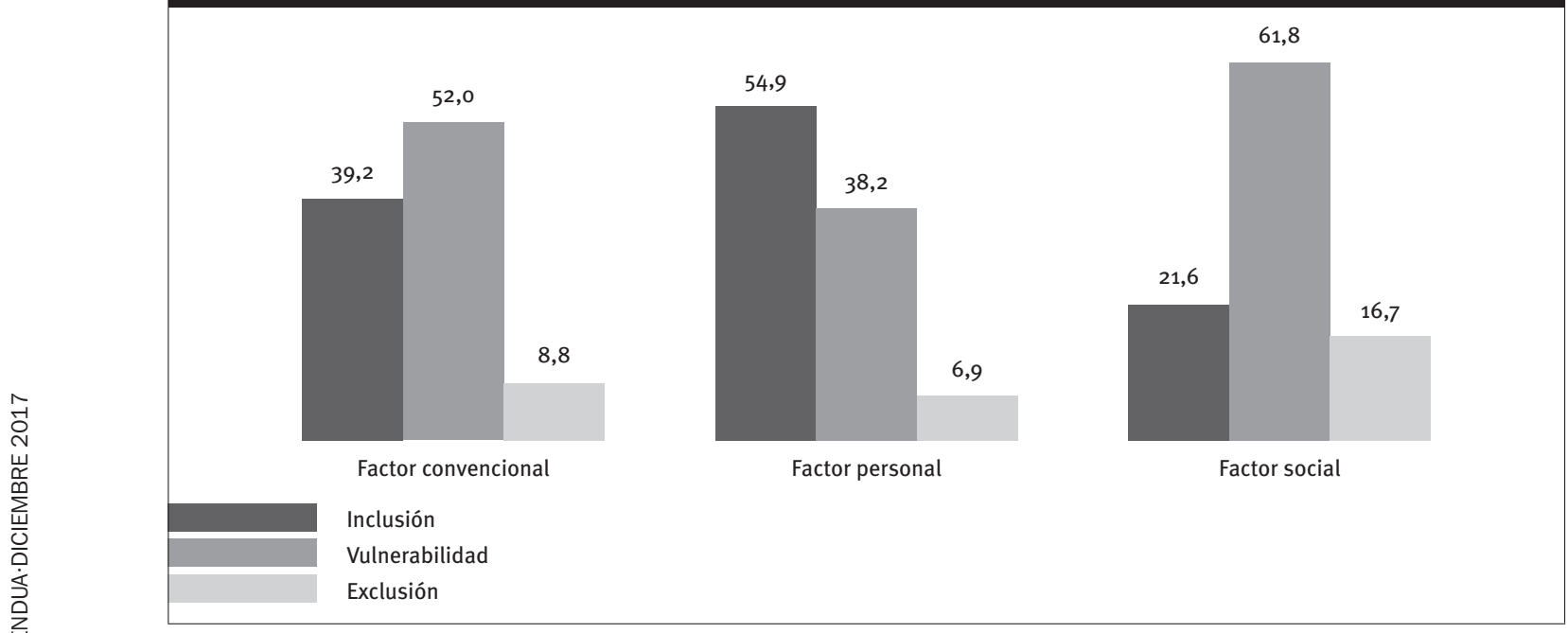

Fuente: Elaboración propia. 
determinar el 'punto de corte' entre las situaciones de exclusión social de las que no lo son: convivencial, personal y social. El análisis de estos indicadores pone de manifiesto las carencias de apoyo social provenientes de redes primarias y secundarias, así como las carencias en los recursos personales, y resulta fundamental para señalar las razones que determinan las situaciones de exclusión/inclusión. De los datos obtenidos en el estudio, se deriva que el peso fundamental en las situaciones de exclusión social recaía en los factores sociales, dado que en el $78,5 \%$ de las personas entrevistadas los indicadores vinculados a la dimensión social correspondían a la situación de vulnerabilidad o exclusión, frente al $60,8 \%$ de la dimensión convivencial y al $45,1 \%$ de la dimensión personal.

\section{Conclusiones}

\section{El Estudio-diagnóstico de situación y necesidades de las personas con discapacidad física de Gipuzkoa se presenta como una contribución de elkartu a la innovación e investigación social en el ámbito del diseño y ejecución de las políticas sociales dirigidas a alcanzar una sociedad plenamente inclusiva y cimentada en la igualdad de oportunidades de toda la ciudadanía. Desde esta perspectiva, el estudio pone de relieve la imperiosa necesidad de guiar las políticas públicas orientadas a las personas en situación o riesgo de exclusión social desde un enfoque basado en los derechos humanos, dado que las políticas sociales constituyen un instrumento fundamental para garantizar los derechos económicos, sociales y culturales, reconocidos como derechos fundamentales para las personas.}

El contexto de crisis económica ha traído consigo un preocupante retroceso de esta perspectiva de derechos humanos universales, y en el ámbito de las políticas sociales se observa que proliferan concepciones y actitudes de carácter asistencialista y pseudosolidario, que, lejos de promover la igualdad de oportunidades de todos los seres humanos, han contribuido a consolidar y ahondar la desigualdad e injusticia social. Las anunciadas reformas de las normas que configuran la arquitectura institucional en el ámbito estatal y autonómico constituyen, de esta forma, una oportunidad apropiada para impulsar, más allá de cuestiones territoriales o competenciales, un adecuado enfoque de los derechos sociales, que permita que las personas en situación de mayor vulnerabilidad sean reconocidas plenamente como titulares de derechos fundamentales, y no sólo como usuarias de prestaciones y servicios sociales. En esta línea, merece destacarse que la entrada en vigor de la actual Ley de Servicios Sociales del País Vasco supuso un hito fundamental en el reconocimiento del derecho subjetivo a los servicios sociales, constituido en un derecho de ciudadanía, al construir un sistema de servicios sociales formado por una red articulada de prestaciones y servicios para dar respuesta a las necesidades y retos sociales, y conformar un auténtico pilar del Estado del bienestar, equiparable a otros sistemas plenamente consolidados.

Sin embargo, el desarrollo posterior de la citada ley, en especial en lo referido a la elaboración y aprobación de la Cartera de Prestaciones y Servicios, y del Plan Estratégico de Servicios Sociales, ha puesto en cuestión el principio de universalidad previsto en aquélla. La pluralidad política representada en las diversas instituciones del País Vasco, el contexto de crisis económica o la ausencia de un liderazgo social y político en materia de servicios sociales son factores que, entre otros, han dilatado en el tiempo un acuerdo interinstitucional para la aprobación de la Cartera de Prestaciones y Servicios, y han provocado un encorsetamiento y dilución en el contenido de numerosos recursos y servicios dirigidos a personas en situación o riesgo de exclusión social. La imperiosa necesidad de un consenso institucional y político, así como la disponibilidad presupuestaria presente y futura han primado sobre el reconocimiento y desarrollo del derecho subjetivo a los servicios sociales como derecho de ciudadanía, haciendo decaer de la Cartera determinadas prestaciones y servicios fundamentales para alcanzar una verdadera igualdad y equidad social, o estableciendo rigurosos y exhaustivos requisitos de acceso que restan valor y eficacia a derechos presuntamente subjetivos. Muestra de ello es la inexistencia en la Cartera de servicios y prestaciones verdaderamente dirigidos a promover modelos de vida independiente entre las personas con discapacidad física, más allá de la ineludible aplicación del Sistema para la Autonomía y Atención a la Dependencia (SAAD), lo cual impide su configuración como derecho subjetivo, y provoca un reconocimiento y desarrollo institucional de carácter voluntario y sujeto a disponibilidad presupuestaria.

La consolidación del derecho subjetivo a los servicios sociales requiere también abordar el reto de definir el modelo adecuado de financiación del sistema vasco de servicios sociales para dotarlo de estabilidad, eficiencia, sostenibilidad y seguridad que permitan abordar de forma oportuna los desafíos presentes y futuros asociados a los cambios sociales, demográficos y económicos. Resulta imprescindible abrir un debate riguroso y alejado de las disputas sociales y políticas, participado por todos los agentes que intervienen en el ámbito de los servicios sociales, que permita alcanzar un diagnóstico compartido y un acuerdo unánime sobre el modelo de financiación de un sistema que presenta una demanda creciente y en progresiva especialización, y cuya viabilidad puede peligrar si no se sientan adecuadamente las bases de su sostenibilidad económica.

El papel del tercer sector en este debate sobre el modelo de financiación, y en el conjunto de cuestiones del ámbito de los servicios sociales, resulta fundamental, por cuanto representa, como movimiento ciudadano organizado, a las personas en situación de mayor vulnerabilidad social y, 
por tanto, titulares del derecho subjetivo a los servicios sociales. Sin embargo, conviene alertar del creciente papel que las organizaciones del tercer sector desempeñan en la provisión de servicios de responsabilidad pública, en detrimento de la función de incidencia política y transformación social, que requiere indudablemente de las mayores cotas de independencia y autonomía. Así, la defensa y promoción de los derechos sociales de la ciudadanía exige un tercer sector que priorice, desde la promoción de la participación y democracia interna, un enfoque sustentado en los derechos humanos, más que en la mera concepción de personas destinatarias de recursos sociales cuya gestión y expansión constituyan el eje fundamental de actuación.

En este sentido, resulta fundamental promover medidas dirigidas a profundizar en la participación real y efectiva del tercer sector en el diseño, elaboración, seguimiento y evaluación de las políticas sociales o de cualquier ámbito de actuación pública que pueda incidir en los derechos de las personas en situación o riesgo de exclusión social, explorando incluso la potencialidad del carácter preceptivo y vinculante de dicha intervención, superando así los modelos de participación sustentados únicamente en los órganos consultivos y meramente informativos.

La desmesurada privatización de los servicios sociales constituye otro de los efectos de la preeminente función del tercer sector en la provisión de servicios de responsabilidad pública, especialmente preocupante cuando se trata de organizaciones no vinculadas históricamente a un determinado colectivo o en las que éste no cuente con participación alguna más allá de la recepción de un determinado servicio, o en las que no han contribuido a gestar o desarrollar el servicio objeto de prestación.

En lo referido a las políticas públicas en materia de discapacidad, el estudio realizado por elkartu las aborda desde un enfoque sustentado en el respeto y promoción de los derechos de las personas con discapacidad, apoyándose fundamentalmente en los principios consagrados por la Convención Internacional sobre los Derechos de las Personas con Discapacidad, que vino a superar la perspectiva asistencial para adoptar una óptica basada en la consideración de las personas con discapacidad como sujetos de derechos, y no como meros sujetos objeto de atención y protección.

A este respecto, se alerta del riesgo de equiparación entre los conceptos de discapacidad y dependencia que conllevan las actuales políticas en este ámbito. Así, tras la puesta en funcionamiento del Sistema para la Autonomía y Atención a la Dependencia se ha tendido a establecer el reconocimiento de la situación de dependencia como requisito de acceso para los diferentes recursos y prestaciones, resultando insuficiente la acreditación de la discapacidad. Estando justificado este hecho en aquellos recursos vinculados a la necesidad de asistencia de una tercera persona para el desempeño de las actividades básicas de la vida diaria, ello no debe llevar a equiparar discapacidad y dependencia, exigiendo esta última en todo tipo de situaciones, dado que ello excluiría de los sistemas de protección social a las personas con discapacidad que no tienen reconocida la situación de dependencia. Asimismo, esta tendencia no hace sino retroceder a concepciones meramente asistencialistas de la atención a las personas con discapacidad, obstruyendo el avance del modelo social conceptualmente reconocido y legalmente instaurado.

Por otra parte, la situación y necesidades de las personas con discapacidad son objeto de análisis en el estudio desde una visión de normalización y transversalidad de las políticas y actuaciones públicas, eludiendo la promoción de medidas y actuaciones específicas para personas con discapacidad que no hacen sino contribuir a la colectivización de los sistemas públicos de protección social. Para ello, ha resultado fundamental la puesta en práctica del Instrumento oficial de Valoración de la Exclusión Social, que permite determinar objetivamente la situación en la que se encuentran las personas con discapacidad física desde la perspectiva de la exclusión social, profundizando así en el conocimiento de dos realidades, discapacidad y exclusión social, íntimamente vinculadas desde un punto de vista conceptual, pero poco acreditadas desde el metodológico.

Los resultados del estudio reflejan una incidencia notablemente superior de las situaciones de exclusión social entre las personas con discapacidad física, en comparación con el conjunto de la población, por lo que la discapacidad se constata como un componente determinante para que las distintas dimensiones que inciden en las situaciones de inclusión o exclusión social inclinen la balanza hacia procesos de exclusión o alejamiento de los ámbitos de participación social y pleno ejercicio de los derechos de ciudadanía. Asimismo, la aplicación de la herramienta de diagnóstico ha permitido determinar que, siendo relevantes los factores convivenciales y personales, el peso fundamental en las situaciones de exclusión social corresponde a los factores sociales, entendidos éstos como aquellos que permiten o, en su caso, impiden, la plena participación de las personas en su entorno comunitario.

Por tanto, el abordaje de las situaciones de exclusión social requiere de políticas decididas a favor del respeto y promoción de los derechos humanos en el diseño, planificación, desarrollo y evaluación de las políticas públicas en materia de discapacidad, rehuyendo de las medidas sustentadas en concepciones asistencialistas ya superadas, que consolidan la especificidad y la consecuente 
segregación social. En esta línea, el estudio señala que son cinco los pilares sobre los que han de sustentarse las actuaciones de prevención e intervención de la exclusión social entre las personas con discapacidad física: educación inclusiva; empleo en un entorno laboral inclusivo, ordinario y accesible; modelo de vida independiente; accesibilidad universal y diseño para todas las personas; $y$ participación plena y real.

En efecto, los datos resultantes en las diferentes áreas objeto de análisis (situación laboral, grado de pobreza, niveles de inclusión/exclusión) evidencian que la educación constituye un factor determinante en el desarrollo de la trayectoria vital de las personas con discapacidad física. De ahí que resulte transcendental garantizar una educación plenamente inclusiva desde las edades más tempranas, impidiendo que la ausencia de apoyos, las carencias en materia de accesibilidad, las barreras actitudinales u otras circunstancias se conviertan en impedimentos para adquirir la formación adecuada que permita llevar a cabo un proyecto vital basado en los principios de normalización e igualdad de oportunidades. Es fundamental asimismo que el carácter inclusivo del sistema educativo se manifieste en todos aquellos aspectos que lo componen (participación en actividades extraescolares dentro y fuera del centro escolar, participación en los recreos, servicios de transporte, promoción de valores sociales), pues de ello depende en buena parte que las personas con discapacidad puedan tejer las redes personales y sociales que puedan perdurar a lo largo de su vida y, en consecuencia, permitan contribuir a su empoderamiento, autonomía personal y plena inclusión social.

La adquisición y desarrollo de competencias personales, sociales y, en su caso, profesionales, que permitan a las personas con discapacidad física participar activamente en la sociedad no ha de limitarse al sistema educativo, sino que debe extenderse a las vías no formales que permiten garantizar un aprendizaje a lo largo de la vida. El acceso en condiciones de igualdad al aprendizaje a lo largo de la vida resulta especialmente relevante para aquellas personas con discapacidad que, por diferentes motivos, carecen de la expectativa de acceder al mercado laboral, pero aspiran a cultivar y ampliar sus conocimientos para promover su desarrollo personal y social y, en definitiva, participar como ciudadanos y ciudadanas activas de su entorno comunitario.

Y en este ámbito, no puede obviarse la importancia que cobra hoy día la adquisición y desarrollo de conocimientos en el área de las tecnologías de la información y la comunicación, por tratarse de instrumentos que se han convertido en imprescindibles como fuentes de información y de comunicación personal, y por tanto, de participación social. Resulta imprescindible, en consecuencia, garantizar a las personas con discapacidad el acceso a los dispositivos y adaptaciones necesarias que les permitan hacer uso de estos sistemas y productos tecnológicos, así como la adecuada formación que contribuya a evitar los riesgos de la brecha digital.

El acceso al mercado laboral en condiciones de igualdad cuando se dan las condiciones personales y profesionales necesarias constituye otro de los eslabones para alcanzar la inclusión social de las personas con discapacidad. Y en este ámbito, el estudio llevado cabo pone de relieve la profunda preocupación existente en un sector del movimiento asociativo y del propio colectivo de personas con discapacidad ante la ausencia de verdaderas políticas laborales que impulsen el acceso a un empleo en un entorno laboral abierto, inclusivo y accesible en los términos establecidos en Convención Internacional sobre los Derechos de las Personas con Discapacidad.

Así, las políticas y medidas adoptadas a lo largo de los últimos años, acentuadas en el transcurso de la denominada crisis económica, han impulsado sin tapujos la consolidación y expansión del mercado laboral protegido para las personas con discapacidad, desbaratando las orientaciones establecidas por la propia Administración, en colaboración con los diferentes agentes sociales, en un hito tan relevante como el Plan para la Incorporación de Personas con Discapacidad al Mercado Laboral Ordinario de la Comunidad Autónoma del País Vasco (2004-2006). Siendo el empleo protegido un instrumento de indudable valor para garantizar el derecho al empleo de las personas que, por sus circunstancias funcionales, personales o sociales, no podrían acceder a un empleo en el mercado laboral ordinario, el devenir de los años permite afirmar que para una parte importante del colectivo de personas con discapacidad física esta modalidad de empleo se ha convertido en un fin en sí misma, en lugar de constituir un eslabón en el proceso de incorporación a un empleo inclusivo y en igualdad de oportunidades con el resto de la ciudadanía, tal y como dispone la normativa reguladora de los centros especiales de empleo.

Asimismo, las propias medidas públicas encaminadas a impulsar el empleo protegido y las políticas de desarrollo y diversificación de los centros especiales de empleo han provocado que accedan a ellos trabajadores que, teniendo reconocida administrativamente la condición de personas con discapacidad, podrían incorporarse a la empresa ordinaria si se adoptaran las políticas de empleo inclusivo idóneas, lo cual conlleva mayores dificultades de acceso de las personas con mayores limitaciones funcionales y, en consecuencia, más obstáculos para la incorporación al mercado laboral ordinario.

El escenario actual corre el riesgo de desvirtuar los fines y principios para los que se articuló en sus orígenes el empleo protegido, por lo que resulta imprescindible, junto con el mantenimiento del respaldo público a esta modalidad de empleo, un 
compromiso decidido y preferencial del sistema vasco de empleo en favor de la promoción de un empleo en un entorno laboral abierto, inclusivo y accesible para las personas con discapacidad, como instrumento para garantizar unas condiciones laborales dignas y sustentadas en la igualdad de oportunidades. Ello requiere, entre otras medidas, de una evaluación y redistribución de las ayudas públicas en materia de empleo, de una adecuada coordinación de los diferentes sistemas públicos (servicios sociales, educación), de un impulso del empleo público como herramienta de incorporación laboral de las personas con discapacidad, de estrategias innovadoras en la colaboración con las empresas, de una revisión del sistema de medidas alternativas como forma de eludir la cuota de reserva para personas con discapacidad en las empresas, de la incorporación del desglose del empleo ordinario y protegido en los datos estadísticos, de medidas orientadas a promover el tránsito del empleo protegido al empleo ordinario, de una evaluación de las condiciones laborales en los centros especiales de empleo, o del impulso del emprendimiento entre las personas con discapacidad.

Acometer estas actuaciones requiere, en todo caso, del necesario liderazgo político en el diseño de las estrategias más adecuadas, así como de la implicación y compromiso de todos los agentes sociales, y la asunción por el sistema vasco de empleo de su responsabilidad en todas las actuaciones tendentes a promover el empleo ordinario, más allá de la mera distribución de ayudas públicas y sin que quepa la delegación generalizada de las funciones propias de las políticas activas de empleo en agentes privados cuyos intereses se alinean más con la consolidación del empleo protegido que con un verdadero compromiso en favor del empleo digno y la igualdad de oportunidades de las personas con discapacidad en el ámbito laboral.

Si hablamos de factores decisivos para prevenir la exclusión social de las personas con discapacidad o para intervenir ante aquélla, merece especial atención la promoción del modelo de vida independiente, en virtud del cual la persona con discapacidad ejerce el poder de decisión sobre su propia existencia y participa activamente en la vida de su comunidad, conforme al derecho al libre desarrollo de la personalidad. Este derecho a vivir de forma independiente y a ser incluido en la comunidad implica necesariamente que la persona con discapacidad tenga la oportunidad de elegir su lugar de residencia y dónde y con quién vivir, en igualdad de condiciones que las demás personas, sin verse obligada a vivir con arreglo a un sistema de vida específico. Por tanto, de acuerdo con este marco conceptual y normativo, las políticas públicas habrían de estar preferentemente orientadas al mantenimiento de las personas con discapacidad en su entorno habitual, articulando para ello fórmulas de apoyo personal, técnico, económico y de alojamiento que promuevan la autonomía personal y el acceso y utilización de los servicios comunitarios.
En este sentido, resulta inaplazable un mayor impulso de los programas y recursos dirigidos a proveer a las personas con discapacidad y en situación de dependencia de la necesaria asistencia personal que posibilite promover su autonomía personal y llevar a cabo una vida independiente. El reciente acuerdo adoptado en el ámbito autonómico en relación con la Cartera de Prestaciones y Servicios del Sistema Vasco de Servicios Sociales constituye claramente una oportunidad perdida para reconocer como derecho subjetivo los programas de asistencia personal, dejando descansar en la arbitraria voluntad de las instituciones forales el complemento de las insuficientes y limitadas prestaciones reconocidas en el Sistema para la Autonomía y Atención a la Dependencia.

Al igual que la asistencia personal, los apoyos técnicos resultan fundamentales para promover la autonomía personal y garantizar la efectividad de una vida independiente en interacción con el entorno comunitario. Siendo así, resulta particularmente censurable el retroceso sufrido en los últimos años en la gestión de los programas públicos dirigidos a proveer de dichos productos a las personas con discapacidad, especialmente por las restricciones impuestas en los diferentes catálogos de productos, así como por las cuantías reconocidas. Por tanto, la trascendencia de este derecho requiere revisar los modelos de gestión vigentes, así como una mayor coordinación y cooperación de las instituciones públicas con competencias en esta materia, de manera que, gracias a una mayor implicación económica y un impulso de la innovación tecnológica que redunde en la calidad de vida de las personas con discapacidad, se alcance la consolidación del derecho a gozar de los productos de apoyo necesarios que garanticen la autonomía personal y la plena participación comunitaria.

El derecho a una vivienda digna, adecuada y accesible, reconocido como derecho subjetivo por el marco jurídico autonómico vigente, constituye una condición fundamental para iniciar proyectos de vida independiente, y el estudio realizado pone de manifiesto las carencias existentes en esta materia, sobre todo en lo referido al acceso al mercado libre. Las medidas de acción positiva adoptadas en la regulación de la vivienda pública para promover el acceso de las personas con movilidad reducida han permitido alcanzar un considerable nivel de disfrute de viviendas de protección oficial, tanto de propiedad o derecho de superficie como de alquiler. Sin embargo, los datos ofrecidos muestran un escaso nivel de acceso de las personas con discapacidad física a la modalidad de alquiler libre en comparación con el conjunto de la población, siendo las carencias de accesibilidad de las viviendas la razón fundamental.

Por tanto, las políticas públicas de vivienda han de profundizar en las medidas dirigidas a garantizar el derecho de las personas con discapacidad a una vivienda accesible, incorporando en la regulación de 
acceso a la vivienda, tanto en la modalidad pública como privada, así como en las ayudas establecidas para la rehabilitación, el objetivo fundamental de alcanzar un parque de viviendas accesibles suficiente para dar respuesta a la necesidad de vivienda de las personas con discapacidad. De lo contrario, seguirán siendo muchas las personas que, teniendo una discapacidad o adquiriendo una en determinado momento, no puedan iniciar o continuar un proyecto vital con plena autonomía y con el poder real de decisión sobre su propia existencia, debido a la imposibilidad de disponer de una vivienda digna, adecuada y accesible.

La garantía del derecho a la vivienda, junto con el acceso a los apoyos personales y técnicos adecuados, inciden decisivamente en el derecho de las personas con discapacidad a no verse en la obligación de vivir con arreglo a un sistema de vida específico, es decir, a sufrir la institucionalización como única alternativa viable. $Y$ es precisamente en el ámbito de los recursos institucionales de alojamiento donde el estudio realizado muestra algunos de los datos y conclusiones más alarmantes, que se han visto confirmados por las valoraciones manifestadas por las personas entrevistadas y en el grupo de discusión organizado al respecto. Los niveles de exclusión social y de pobreza de las personas institucionalizadas, la satisfacción con la asistencia recibida o la participación en el entorno comunitario han sido objeto de análisis y han de ser necesariamente tomados como indicadores para diseñar un nuevo modelo de atención en los recursos residenciales para personas con discapacidad que, más allá de meros discursos retóricos, debe estar inevitablemente basado en los derechos de las personas usuarias y en la efectiva materialización del modelo social de la discapacidad.

Resulta también inaplazable configurar recursos y servicios de alojamiento adecuados para las personas con discapacidad física, especialmente en lo referido a los recursos de atención diurna, de manera que se configure una red de servicios flexibles y comunicados entre sí que, mediante la planificación individual y la participación de la propia persona usuaria, promuevan la autonomía personal y fomenten la plena inclusión social.

Por otra parte, no puede obviarse que la garantía de unos ingresos mínimos resulta fundamental para la viabilidad del modelo de vida independiente, junto con los factores antes indicados. Y en este ámbito, al igual que en otros, ha de ponerse en valor el concepto de medida de acción positiva que, lejos de constituir un privilegio de las personas con discapacidad, permite compensar el sobrecoste que ésta acarrea. Así, dignificar el importe de las pensiones - especialmente de las no contributivas-, permitir la compatibilidad de la prestación por hijo a cargo con la renta de garantía de ingresos, impulsar el acceso al empleo ordinario, flexibilizar y promover la compatibilidad de las pensiones y el desempeño de una actividad laboral retribuida, garantizar unas condiciones laborales dignas en el ámbito del empleo protegido, prescindir del copago de las personas usuarias de los servicios y recursos sociales, o en su defecto, proceder a un ajuste razonable que permita el ejercicio de los derechos de ciudadanía, o actualizar los importes de las ayudas públicas para la adquisición de productos de apoyo son, entre otras, medidas que contribuirían a un mayor bienestar de las personas con discapacidad y, por tanto, a su autonomía personal e inclusión social.

La promoción de la accesibilidad universal como condición que deben cumplir los entornos, procesos, bienes, productos y servicios para que puedan ser comprensibles, utilizables y practicables por todas las personas de la forma más autónoma posible constituye una herramienta decisiva para garantizar la igualdad de oportunidades de toda la ciudadanía y prevenir situaciones de exclusión social. Desde esta perspectiva, el estudio llevado a cabo pone de manifiesto, tanto en su aspecto cuantitativo como cualitativo, la especial preocupación que provoca este asunto en el colectivo de personas con discapacidad física, por tratarse de un derecho que permite, obstaculiza o impide el acceso a otros derechos fundamentales.

Habiéndose producido hace ya dos décadas un notable impulso de las políticas de promoción de la accesibilidad que desembocaron en el actual marco jurídico en esta materia, se constatan en la actualidad graves incumplimientos y carencias, así como una evidente ausencia de avances, lo cual provoca que una parte importante de la población no pueda hacer efectivos sus derechos de ciudadanía debido a entornos, bienes y servicios que producen discapacidad y situaciones de dependencia. Existen en el estudio numerosas referencias a las carencias de accesibilidad en ámbitos como la vivienda, el empleo, el transporte, los espacios públicos, las tecnologías de la información y la comunicación, la educación o los establecimientos de uso público, siendo el denominador común de todos ellos la generación de situaciones de exclusión social del todo inaceptables en pleno siglo XXI.

Por tanto, se hace preciso abandonar los discursos infundadamente autocomplacientes e iniciar un nuevo y ambicioso ciclo en el diseño, aplicación, evaluación y control de las medidas orientadas a garantizar el derecho a la accesibilidad universal. Estas medidas deben pivotar en un patente liderazgo institucional que abogue sin reservas por instaurar una concepción de la accesibilidad universal desde la óptica del derecho fundamental de toda la ciudadanía, y no sólo de las personas con discapacidad, implantando el diseño universal como elemento indispensable de las políticas y actuaciones públicas; y que fomente la participación real y efectiva de las personas con discapacidad y de las entidades que las representan.

El derecho a la participación plena y efectiva como instrumento de empoderamiento personal y colectivo 
es el último pilar que el estudio realizado propone como factor para prevenir la exclusión social. Así, la participación de las personas con discapacidad en la vida política, económica, social, educativa, laboral y cultural se erige como el indicador más efectivo de la plena inclusión social, debiendo, por tanto, adoptarse todas las medidas necesarias que permitan garantizar y hacer efectivo este derecho.

La trascendencia de la participación social se acredita objetivamente a través de la aplicación del instrumento oficial de valoración de la exclusión social, que señala el ámbito social, es decir, la interacción de la persona con discapacidad física con su entorno comunitario, como el factor fundamental para desembocar en situaciones de exclusión social. Por tanto, se hace preciso promover la plena participación de las personas con discapacidad en los diversos ámbitos de su entorno, removiendo los obstáculos que puedan limitar el ejercicio efectivo de este derecho en igualdad de oportunidades que el resto de la ciudadanía. Siendo, sin duda, la accesibilidad universal un componente decisivo en este ámbito, cobra mayor sentido reivindicar un nuevo impulso de las políticas y actitudes tendentes a garantizar bienes, servicios y entornos que respeten la diversidad y generen igualdad plena.

El papel de las entidades del tercer sector social como garantes y representantes de la participación social de las personas en situación o riesgo de exclusión social resulta fundamental, lo que exige profundizar en su función de promoción de los movimientos sociales organizados y estrechar los vínculos con las personas que, más allá de percibir diferentes servicios y prestaciones, delegan en cierta manera su confianza y la defensa de sus derechos en organizaciones que han de primar los intereses generales sobre los propios, y la condición de ciudadanía activa de las personas con discapacidad.

En el marco de la participación comunitaria, el derecho al ocio desempeña un papel fundamental que ha de ser objeto de refuerzo y compromiso institucional. En los últimos tiempos, se observa cierta tendencia al tratamiento del ocio desde una perspectiva residual o secundaria, y así se ha reflejado tanto en los documentos estratégicos y normas aprobadas en el ámbito de los servicios sociales como en las medidas presupuestarias adoptadas. Sin embargo, lejos de restringir este derecho, procede reconocer su condición de derecho fundamental y adoptar las medidas de acción positiva necesarias para garantizar su función de instrumento facilitador de la plena inclusión social de las personas con discapacidad en condiciones de igualdad.

En definitiva, los datos y valoraciones contenidos en el Estudio-diagnóstico de situación y necesidades de las personas con discapacidad física de Gipuzkoa aspiran a convertirse en herramientas eficaces para el diseño, prestación, evaluación y mejora de los diferentes sistemas de responsabilidad pública con incidencia en los derechos y la calidad de vida de las personas con discapacidad, así como en instrumento imprescindible en la labor de incidencia de las organizaciones sociales que representan los derechos e intereses de las personas en situación o riesgo de exclusión social.

Con este estudio, elkartu continúa con su trayectoria reivindicativa en favor del colectivo de personas con discapacidad física y con su labor de transformación social para lograr una sociedad basada en la igualdad y la justicia social, en la que no quepan situaciones de exclusión, desigualdad y discriminación. Asimismo, la Federación se compromete a hacer partícipes de los resultados, conclusiones y propuestas al propio colectivo, a los agentes públicos y privados implicados, así como a la sociedad en su conjunto, para aunar voluntades y compromisos en los retos que todavía quedan por afrontar para alcanzar la plena igualdad e inclusión social de las personas con discapacidad física. 
COMISIÓN EUROPEA (2010): Comunicación de la Comisión al Parlamento Europeo, al Consejo, al Comité Económico y Social Europeo y al Comité de las Regiones. Estrategia Europea sobre Discapacidad 2010-2020: un compromiso renovado para una Europa sin barreras, Bruselas, Comisión Europea, com/2010/0636 final [<http://eur-lex.europa.eu/legal-content/ ES/TXT/?uri=celex:52010DC0636>].

DEPARTAMENTO DE EMPLEO Y POLÍTICAS SOCIALES (2015): Plan Estratégico de Servicios Sociales de la CAPV 2016-2019, Vitoria-Gasteiz, Eusko Jaurlaritza-Gobierno Vasco.

DIRECCIÓN DE TRABAJO Y SEGURIDAD SOCIAL (2004): Plan para la Incorporación de Personas con Discapacidad al Mercado Laboral Ordinario de la Comunidad Autónoma del País Vasco (20042006), Vitoria-Gasteiz, Vitoria-Gasteiz, Eusko Jaurlaritza-Gobierno Vasco.

\section{ELKARTU-FEDERACIÓN COORDINADORA DE PERSONAS} CON DISCAPACIDAD FÍSICA DE GIPUZKOA (2015): Estudio-diagnóstico de situación y necesidades de las personas con discapacidad física de Gipuzkoa / Gipuzkoako desgaitasun fisikoa duten pertsonei buruzko azterketadiagnostikoa, Donostia-San Sebastián, elkartu-Federación Coordinadora de Personas con Discapacidad Física de Gipuzkoa [<http:// elkartu.org/pdf/Estudio-diagnostico-desituacion-y-necesidades-de-las-personas-condiscapacidad-fisica-de-Gipuzkoa.pdf〉].

LORENZO GILSANZ, F. (coord.) (2014): VII Informe sobre Exclusión y Desarrollo Social en España, Madrid, Fundación Foessa.
ORGANIZACIÓN DE LAS NACIONES UNIDAS (2006): Convención sobre los Derechos de las Personas con Discapacidad y Protocolo Facultativo, Nueva York, Organización de las Naciones Unidas [<http://www.un.org/disabilities/documents/ convention/convoptprot-s.pdf〉].

PAÍS VASCO (2015): “Decreto 185/2015, de 6 de octubre, de Cartera de Prestaciones y Servicios del Sistema Vasco de Servicios Sociales", Boletín Oficial del País Vasco, no 206, 29-10-15, págs. 1-87 [<https://www.euskadi.eus/y22-bopv/es/ bopv2/datos/2015/10/1504561a.shtml]].

- (2013): “Decreto 385/2013, de 16 de julio, por el que se aprueba el Instrumento de Valoración de la Exclusión Social”, Boletín Oficial del País Vasco, no 149, 7-8-13 [khttps://www.euskadi.eus/ y22-bopv/es/bopv2/datos/2013/08/1303530a. shtml>].

- (2008): "Ley 12/2008, de 5 de diciembre, de Servicios Sociales", Boletín Oficial del País Vasco, nㅡ 246, 24-12-08, págs. 31.840-31.924 [rhttps:// www.euskadi.eus/r47-bopvapps/es/ bopv2/ datos/2008/12/0807143a.shtmls].

SIIS CENTRO DE DOCUMENTACIÓN Y ESTUDIOS (2013): Encuesta de Pobreza y Exclusión Social de Gipuzkoa 2012. Informe de resultados / Gipuzkoako Pobrezia eta Gizarte Bazterketari buruzko Inkesta 2012. Emaitza txostena, Donostia-San Sebastián, Diputación Foral de Gipuzkoa [<http://behagi.eus/files/informes/ encuesta-pobreza-exclusion-social-gipuzkoa. pdf>]. 